\section{Trends in paediatric tubercullosis diagnoses in two South African hospitals early in the COVID-19 pandemic}

To the Editor: In response to the COVID-19 pandemic, South Africa (SA) instituted a countrywide lockdown on 27 March 2020. The lockdown affected the ability of patients to access tuberculosis (TB) services, ${ }^{[1]}$ resulting in an large decline in diagnostic TB Xpert testing. ${ }^{[2]} \mathrm{TB}$ screening and investigation are essential for preventive and therapeutic care for people living with HIV and to diagnose or rule out active TB. ${ }^{[3-6]}$ In contrast to adults, hospital admissions of children with lower respiratory tract infections (LRTIs) decreased dramatically during the lockdown. ${ }^{[7]}$ Moreover, sputum induction and gastric aspirate collection, essential to diagnose TB in children, are aerosol-generating procedures and were curtailed to reduce healthcare worker exposure to SARS-CoV-2.

We describe paediatric TB notification rates in two public sector academic hospitals, Chris Hani Baragwanath Academic Hospital (CHBAH) and Rahima Moosa Mother and Child Hospital (RMMCH), in Johannesburg, SA. Data from 2012 showed that LRTIs accounted for $60 \%$ of paediatric admissions, with $10 \%$ of these children being diagnosed with TB at CHBAH. ${ }^{[8]}$ We analysed routinely collected hospital admission and TB notification data in children aged 0 - 10 years over a 33-month period from January 2018 through September 2020 to evaluate the early impact of the pandemic on paediatric TB diagnosis.

The median (interquartile range (IQR)) number of children admitted to each of the two hospitals per month was significantly lower during the COVID-19 lockdown period (252 (202 - 316)) compared with previous months before the lockdown (705 (485 826)) $(p<0.0001)$ (Table 1). A total of 800 children (649 at $\mathrm{CHBAH}$ and 151 at $\mathrm{RMMCH}$ ) were diagnosed with $\mathrm{TB}$ over the 33-month period. During the 27-month pre-COVID-19 period, there were a median (IQR) of 14 (5 - 25) paediatric TB notifications per month, compared with $3(2-4)(p=0.0003)$ during the COVID-19 lockdown period (Table 1). However, median TB notification rates per 1000 paediatric admissions did not differ significantly between the preCOVID and COVID periods (18/1 000 v. 10/1 000, respectively).

The decline in monthly TB notifications we report is unlikely to be explained by less TB transmission as a result of adult mask wearing and severe restrictions on social mixing, especially as TB notification rates in children admitted to hospital remained stable. However, both the influenza and respiratory syncitial virus seasonal peaks in incidence had not yet been observed in SA in 2020, suggesting that non-pharmaceutical interventions do interrupt droplet pathogen transmission. ${ }^{[9]}$ Alternatively, the lockdown may have reduced child acquisition of TB in non-household settings, where it is posited that most TB transmission takes place. ${ }^{[10]}$ Conversely, delayed diagnosis or interrupted TB treatment in adults could increase the risk of $\mathrm{TB}$ exposure for children in their households, leading to higher TB transmission. It is more likely that hard barriers, or caregiver reluctance, to access routine health services during the pandemic better explain declines in paediatric admissions and TB notification rates. As the SA lockdown eases, an increase in TB notifications is expected, potentially with more severe manifestations likely to be due to delayed TB diagnoses in adults.

Acknowledgements. We would like to acknowledge the CHBAH and RMMCH management, staff and study team, for making this work a success.

Funding. This study was funded by a grant from the National Institutes of Health (5R01 AI129708).

\section{Limakatso Lebina, Mthokozisi Dube, Khuthadzo Hlongwane, Heena Brahmbatt \\ Perinatal HIV Research Unit, South African Medical Research Council Soweto Matlosana Collaborating Centre for HIV/AIDS and TB, Faculty of Health Sciences, University of the Witwatersrand, Johannesburg, South Africa \\ lebinal@phru.co.za}

\section{Sanjay G Lala}

Perinatal HIV Research Unit, South African Medical Research Council Soweto Matlosana Collaborating Centre for HIV/AIDS and TB, Faculty of Health Sciences, University of the Witwatersrand, Johannesburg, South Africa; and Paediatric Education and Research Ladder, Department of Paediatrics, Faculty of Health Sciences, University of the Witwatersrand, Johannesburg, South Africa

Table 1. New TB notification rates, before and during the COVID-19 lockdown, in children aged 0 - 10 years admitted to two public hospitals in Johannesburg, South Africa, between January 2018 and September 2020

\begin{tabular}{|c|c|c|c|}
\hline Variables & $\begin{array}{l}\text { Pre-COVID-19 lockdown, } \\
\text { median (IQR) }\end{array}$ & $\begin{array}{l}\text { During COVID-19 lockdown, } \\
\text { median (IQR) }\end{array}$ & $p$-value \\
\hline \multicolumn{4}{|c|}{ Monthly hospital admissions } \\
\hline Overall & $705(485-826)$ & $252(202-316)$ & $<0.0001^{*}$ \\
\hline СНВAH & $818(767-920)$ & $310(260-316)$ & $0.0002^{*}$ \\
\hline RMMCH & $485(436-620)$ & $218(215-315)$ & $0.0002^{*}$ \\
\hline \multicolumn{4}{|c|}{ Monthly TB notifications } \\
\hline Overall & $14(5-25)$ & $3(2-6)$ & $0.0003^{*}$ \\
\hline СНВАН & $25(20-29)$ & $4(2-8)$ & $0.0003^{*}$ \\
\hline $\mathrm{RMMCH}$ & $5(3-6)$ & $3(2-3)$ & 0.0284 \\
\hline \multicolumn{4}{|c|}{ Monthly new TB notifications/1 000 admissions } \\
\hline Overall & $18(9-29)$ & $10(6-20)$ & 0.2123 \\
\hline CHBAH & $28(25-33)$ & $16(6-36)$ & 0.2301 \\
\hline $\mathrm{RMMCH}$ & $9(7-12)$ & $9(6-14)$ & 0.2823 \\
\hline
\end{tabular}




\section{Gary Reubenson}

Empilweni Service and Research Unit, Rahima Moosa Mother and Child Hospital and Department of Paediatrics and Child Health, Faculty of Health Sciences, University of the Witwatersrand, Johannesburg, South Africa

\section{Neil Martinson}

Perinatal HIV Research Unit, South African Medical Research Council Soweto Matlosana Collaborating Centre for HIV/AIDS and TB, Faculty of Health Sciences, University of the Witwatersrand, Johannesburg, South Africa; and Center for TB Research, Johns Hopkins University, Baltimore, Md, USA

1. Statistics SA. Behavioural and health impacts of the COVID-19 pandemic in South Africa. Pretoria Stats SA, 2020. http://www.statssa.gov.za/publications/Report-00-80-02/Report-00-80-022020.pd (accessed 23 September 2020)

2. Ismail N, Moultrie H. Impact of COVID-19 interventions on TB testing in South Africa. Johannesbur: Centre for Tuberculosis, National Institute for Communicable Diseases, 2020. https://tbsouthafrica. org.za/sites/default/files/news/20200510\%20Impact-of-Covid-19-interventions-on-TB-testing-inSouth-Africa-10-May-2020 pdf (accessed 23 September 2020).
3. Naidoo P, Theron G, Rangaka MX, et al. The South African tuberculosis care cascade: Estimated losses and methodological challenges. J Infect Dis 2017;216(Suppl 7):S702-S713. https://doi.org/10.1093/ nfdis/jix 335

4. World Health Organization. Systematic screening for active tuberculosis, Principles and recommendations. Geneva: WHO Document Production Services, 2013. https://www.who.int/tb/ tbscreening/en/ (accessed 29 September 2020).

5. Salazar-Austin N, Dowdy DW, Chaisson RE, Golub JE. Seventy years of tuberculosis prevention: Efficacy, effectiveness, toxicity, durability, and duration. Am J Epidemiol 2019;188(12):2078-2085. https://doi.org/10.1093/aje/kwz172

6. Dheda K. 'Mind the gap': Detecting the missing TB cases through active case finding. Int J Tuberc Lung Dis 2018;22(10):1115-1115. https://doi.org/10.5588/ijtld.18.0583

7. Krivec U, Kofol Seliger A, Tursic J. COVID-19 lockdown dropped the rate of paediatric asthma admissions. Arch Dis Child 2020;105:809-810. https://doi.org/10.1136/archdischild-2020-319522

8. Brink J, Pettifor JM, Lala SG. The prevalence of malnutrition in children admitted to a general paediatric ward at the Chris Hani Baragwanath Academic Hospital: A cross-sectional survey. S Afr J Child Health 2014;8(3):112-116. https://doi.org/10.7196/SAJCH.787

9. National Institute for Communicable Diseases. COVID-19 weekly epidemiology brief: Week 37 2020. https://www.nicd.ac.za/wp-content/uploads/2020/09/COVID-19-Weekly-Epidemiology-Briefweek-37pdf (accessed 5 October 2020).

10. Wood R, Johnstone-Robertson S, Uys P, et al. Tuberculosis transmission to young children in a South African community: Modeling household and community infection risks. Clin Infect Dis 2010;51(4):401-408. https://doi.org/10.1086/65512

S Afr Med J 2020;110(12):1149-1150. https://doi.org/10.7196/SAMJ.2020.v110i12.15386 